\title{
EL ETRUSCO COMO INDOEUROPEO ANATOLIO: VIEJOS Y NUEVOS ARGUMENTOS
}

FRANCISCO R. ADRADOS

El autor vuelve sobre su teoría, que considera el etrusco como un derivado del indoeuropeo arcaico, conservado en anatolio. Estudia este tema desde el punto de vista lingüístico: sg. = Plu., N. = Ac., N. = G., flexión nominal, adjetival y verbal (monotemática) de tipo IE arcaico, todo ello comparado con el IE anatolio arcaico, pre-brugmanniano. Estudia y critica, también, las opiniones de los diferentes lingüistas. Sigue pensando que los etruscos llegaron a Italia hacia el siglo VII a. C. o antes, trayendo desde Asia Menor un Indoeuropeo arcaico que, naturalmente, adquirió secundariamente algunos rasgos itálicos. - Critica las opiniones de varios lingüistas y, sobre todo, ciertas teorías de base nacionalista que deberían ser ya retiradas. Los arqueólogos han tendido un velo de silencio sobre problemas lingüísticos que les son ajenos.
The author exposes again his theory, which considers Etruscan as a derivative of the most ancient Indoeuropean, preserved in some Anatolian languages. He studies this problem from a linguistic point of view: sg. = Pl., N. = Ac., N. = G., nominal, adjectival and verbal (monothematic) flexion of an archaic IE type, comparing Etruscan with the pre-brugmannian, archaic Indoeuropean. He maintains his opinion that the Etruscans arived in Italy in the VII century b. C. or before, bringing an archaic Indoeuropean language from Asia Minor. Naturally, it adquired secundarily some Italic elements. - He criticizes the opinions of several linguists and as well some theories of nationalistic nature which should be withdrawn now. Archaeologists have silenced linguistic problems which are important, but alien to them.

\section{El etrusco, lengua paria.}

Mala suerte ha tenido el etrusco cuando algunos lingüistas hemos querido incorporarlo al cuadro de las lenguas indoeuropeas. Massimo Pittau ha explicado muy claramente ${ }^{1}$ el veto que la escuela arqueológica italiana, siguiendo a M. Pallottino, ha impuesto a cualquier intento de comparar el

1 La lingua etrusca. Grammatica e Lessico, Núoro, Insula Edizioni, 1997, p. 28 ss. Añado algunas consideraciones que en su día me envió R. Ambrosini por carta: «L' ombra di Pallottino (y alude a Cristofani) impedisce addiritura di trattare il tema senza essere automaticamente pressi per pazzi ... le sue idee verranno qui tacciate ingiustamente ... l' ambiente italiano al quale in genere dà fatidio che qualcuno si occupi di etrusco, tranne nella forma asetticamente descrittiva e ripetitiva del dato».

EMERITA. Revista de Lingüística y Filología Clásica (EM) — ISSN 0013 - 6662 
etrusco con otras lenguas. Siguiendo a Dionisio de Halicarnaso, esta escuela decretó el aislamiento del etrusco. Hablar de "orígenes" del pueblo etrusco (y su lengua) sería algo contra natura, habría un "farsi" del etrusco dentro de Italia, como el del francés en Francia (aunque nadie niega que venga del latín) ${ }^{2}$.

Hasta se ha intentado de varias maneras negar una relación con la lengua de la conocida estela de Lemnos, algo que salta a la vista de cualquiera que ponga en ella sus ojos. Algunos lo reconocen, pese al escepticismo comparativista.

Desde luego, que el etrusco haya incorporado en Italia léxico y hasta elementos gramaticales itálicos y otros, es de sobra aceptable. Pero se ha prohibido prácticamente compararlo con otras lenguas: se ha convertido en una especie de paria. Y eso que la lista de los lingüistas que de un modo u otro han incluido al etrusco dentro del grupo indoeuropeo es impresionante: Corssen, Bugge, Thomopoulos, Vetter, Trombetti, Sapir, Buonamici, Goldmann, Kretschmer, Ribezzo, Schachermeyr, Carnoy, Georgiev, Austin, Westcott, Morandi, Woodhuizen, Bader, el propio Pittau ${ }^{3}$. Todo lo más, se habla de "afinidades" (M. Cristofani ${ }^{4}$ ).

Lingüistas italianos suelen hallar en el etrusco toda clase de elementos diversos, a la manera de Pallottino. Así M. Durante ${ }^{5}$.

2 Para Pallottino véase «Il problema delle origini etrusche e la preminente incidenza del fatto linguistico nella sua discussione», en Palentologia linguistica. Atti del VI Convegno Internazionale di Linguisti, Brescia, Paideia, 1977, pp. 129-136: el "farsi" sería antes del siglo VII. Los datos culturales y epigráficos harían colocar la constitución del pueblo etrusco antes de ese momento. Dice que se puede pensar en una proto-colonización pelásgica o tirrénica al final del bronce (Bérard, Hencken) o en movimientos por vía terrestre. Pero subraya la fundamental anindoeuropeidad del etrusco, representada fundamentalmente por la serie numeral; las relaciones más o menos claras con el IE en la flexión nominal, pronombres y léxico; la coexistencia de flexión y aglutinación; la toponomástica mediterranea; la relación fragmentaria con lenguas de Asia anterior, la estela de Lemnos. 135. No hay una lengua traida en bloque, hay convergencia de elementos de vario origen. Y estratos: mediterraneo, egeo-anatolio, itálico. Todo confuso por no entrar derechamente en la comparación.

Ob. cit., p. 28 ss. y en diversos lugares de la misma.

4 Introduzione allo studio dell' etrusco, Florencia, 1973. Para él («Perspettive per l' etrusco» en L' etrusco e le lingue dell' Italia antica, Pisa, Giardini, 1985) la única comparación clara del etrusco es con la estela de Lemnos.

5 «Considerazioni intorno al problema de la classificazione dell' etrusco», SMEA 7, 1968, pp. 7-60 y otros trabajos. Halla en el etrusco elementos anatólicos (etr. y luv., lic., het.):

EMERITA. Revista de Lingüística y Filología Clásica (EM) — LXXIII 1, 2005 ISSN 0013-6662 
Más positivo es R. Gusmani, que ha comparado al etrusco con el lidio ${ }^{6}$. $\mathrm{Y}$, a pesar de todo, H. Rix ${ }^{7}$. Pero en general prima un furioso anticomparantivismo, procedente de Pallottino: se prefiere el método combinatorio ${ }^{8}$.

Todo esto es equivocado: se aglomeran datos inconexos, se evita mirar a aquellos con los cuales puede construirse un sistema que no es, ciertamente, el del IE brugmanniano, pero sí el del IE arcaico, como haré ver. Con ciertas diferencias, por supuesto. Por otra parte, la identificación del etrusco con el

-assi-, -alli- (luv.), G. etr. en -s(i), -al(e), étnicos en -mn- (het.), también onomástica (luv. Tarhunt- / etr. Tar $)$, lexicales. Concluye: faltan pruebas de relaciones morfológicas, salvo las formas genitivales (!!), lo que hay son isonimias y isomitias. El núcleo fundamental hay que buscarlo en Occidente, pero algunos datos vienen de Oriente, como puia, Tar- $\chi$-nt. Total, habría un fondo indígena, con aportes culturales orientales del siglo XI o antes. Desvaloriza la estela de Lemnos, igual que Bonfante: «apparenti somiglianze ... materiale ... troppo scarso ed inutilizzabile da una corretta metodologia».

6 R. Gusmani, Lydisches Wörterbuch, Heidelberg, Winter, 1964 ss.

7 En KZ 96, 1982-83, pp. 295-300 (reseña de Pallottino, La langue étrusque, París, Les Belles Letres, 1978, reelaborando cosas anteriores, entre ellas «Die moderne Linguistik und die Beschreibung des Etruskischen», Kadmos 10, 1971, 150-170). Frente al negativismo de P. («imposibilité... de rapporter les faits particuliers à un modèle qui nous soit familier»), reconoce que «nun ist wohl eine genealogische Verwandtschaft bis jetzt nicht nachgewiesen». Quiza era cierto en aquel momento. Pero, para él, se puede hacer un esquema de la flexión nominal. Hace uno con N. y colectivo, dos G., un L., derivados de los dos G. (originalmente adjetivos): un pertinentivo y un Ablativo: a) clen-s-i (cree la -s- de G.), b) larthals, tuteis (e.


Admite la polifuncionalidad de varias formas.

8 Cf. por ej. Ambros J. Pfiffig: «Zum Methodenproblem in der etruskischen Sprachwissenschaft», Kadmos 13, 1975, pp. 137-145. También Giuseppe Franco, Orizzonti Etruschi. Milán, SugarCo Edizioni, 1987: «... para crear el etrusco ha habido factores de varios orígenes ... sería un error considerarlo una manifestación intrusiva como el púnico ...» Habría «fasi di primitiva mediterraneità, di specifiche sollizitazioni egeo-asianiche e di progressiva 'italizzazione'» ... «non è possibile una 'classificazione' dell' etrusco nel senso della vecchia linguistica genealogica ... difficoltà di trovare un inquadramento comparativo soddisfacente ed univoco dei fatti conosciuti». Alude a semejanzas con el IE, lenguas anatólicas y lemnio, pero argumenta con el léxico. Hay que superar, dice, «i simplicismo astratto di una contapposizione fra idue concetti di 'indoeuropeismo' e di 'anindoeuropeismo'». Estos autores desconocen, simplemente, los datos indoeuropeos, que son la espina central del etrusco; que haya préstamos itálicos puede ser cierto. Cf. también Romolo A. Staccili, Il «mistero» della lingua degli Etruschi, Roma, Newton Compton, 1977, p. 337: «l' etrusco non rientra, nella sua struttura, in nessun dei gruppi linguistici noti a noi». Igual en Gli Etruschi: mito e realtà, Newton Compton, 1982. Y A. Prosdocimi, en $L^{\prime}$ etrusco citado, pp. 53-68: no hay parentesco que dé una clave heurística.

EMERITA. Revista de Lingüística y Filología Clásica (EM) — LXXIII 1, 2005 ISSN 0013-6662 
hetita por Georgiev ${ }^{9}$ era precipitada y contribuyó a desacreditar el método comparativo.

Está abandonada, pues, hoy, la línea comparativa: lo que se escribe desde este punto de vista ni se lee ni se cita siquiera. Algo anticientífico, la verdad.

Todo lo más, se ha comparado el etrusco con el rético, probable derivado suyo ${ }^{10}$. También se ha comparado con lenguas de Córcega y Cerdeña (nurágico y sardo). Pero esto se refiere a lenguas occidentales emparentadas de un modo u otro con el etrusco, no a sus orígenes. Los orígenes deben estudiarse mediante la comparación con lenguas indoeuropeas asiáticas que conocemos, no mediante apriorismos.

En este ambiente publiqué dos artículos ${ }^{11}$ en que proponía que el etrusco derivaba del Indoeuropeo anatolio, lo que se insertaba perfectamente en el relato de Heródoto y tantos otros autores que hacían venir a los etruscos de Lidia o de Asia Menor en general. En conexión, se piensa, con las incursiones y asentamientos de los "pueblos del mar", entre los cuales son citados los etruscos en las fuentes egipcias, en 1186 a. C. ${ }^{12}$

No en vano, por lo demás, para los griegos, los tirrenos eran un pueblo que navegaba por el Egeo (hHom. VII 6, Hdt. I 57), Tucídides IV 107 los identificaba con los pelasgos y los colocaba en Lemnos y Atenas.

Mis artículos fueron cuidadosamente olvidados por los etruscólogos que, sin competencia en Lingüística indoeuropea, imponían, sin embargo, su criterio. Y también chocaron con las teorías standard sobre el Indoeuropeo: las de los indoeuropeistas que siguen trabajando con un Indoeuropeo unitario y plano, el de la reconstrucción de Brugmann. ¡Una reconstrucción anterior al desciframiento del hetita y el estudio del Indoeuropeo minorasiático!

Esta no es sino otra prueba del terrible conservadurismo que se ha apoderado de la disciplina científica que es o debe ser la Lingüística Indoeuropea:

\footnotetext{
9 V. Georgiev, Hethitisch und Etruskisch, Sofia, 1962.

10 Así H. Rix, Rätisch und Etruskisch, Innsbruck, 1998. Véase mi reseña en Emerita 69, 2001, p. 359 s.

11 «Etruscan as an IE Anatolian (but not Hittite) Language», JIES 17, 1989 (1990), pp. 363-383; «More on Etruscan as an IE-Anatolian Language», Historische Sprachforschung 107, 1997, pp. 54-76.

12 Cf. C. di Palma, Le origini degli etruschi, Bolonia, 2004, p. 40 ss., con amplia documentación.
}

EMERITA. Revista de Lingüística y Filología Clásica (EM) — LXXIII 1, 2005 ISSN 0013-6662 
avanza en estudios de lenguas particulares, pero en la teoría general está paralizada. Lo triste es cuando nuestros alumnos van a Alemania y regresan con el cerebro lavado.

Llevo muchos años, sin embargo, proponiendo que el Indoeuropeo tuvo varias fases y que la conservada en Asia Menor, fase monotemática que llamo IE II (sin género masc. / fem., ni grados de comparación del adjetivo ni sistema de temas temporales y modales en el verbo, entre otras cosas) es más antigua que la del Indoeuropeo brugmanniano o IE III, el de la reconstruccion tradicional. Algunos lingüistas han trabajado sobre las mismas ideas ${ }^{13}$, pero los más siguen aferrados al esquema de Brugmann: si el hetita carece de femenino, de aoristo, de subjuntivo, etc., es que los ha perdido. Puro apriorismo sin sentido, estoy cansado de luchar contra él.

La crítica de Erich Neu, un hetitólogo muy distinguido, contra mi primer artículo sobre el etrusco ${ }^{14}$. a la cual respondí en el segundo, parte simplemente de que no es capaz de comprender un Indoeuropeo carente del sistema de temas brugmanniano. No lo hay, evidentemente, en etrusco, pero no menos evidentemente, luego volveré sobre ello, pero tamoco en el sistema del más antiguo Indoeuropeo, el conservado en Anatolia (más antiguo aún es el preflexional, IE I, esto no lo he inventado yo). Reconoce Neu que «hay fenómenos ... que dan la impresión de que existen relaciones entre el etrusco y las lenguas indoeuropeas de Anatolia», pero, apoyado en ciertos hechos de detalle (en algunos de los cuales puede tener razón) y, sobre todo, en sus prejuicios contra el vario uso del tema puro en Indoeuropeo, entre otras cosas, se muestra al final escéptico. En realidad, como digo en mi crítica (que no repito aquí), no hace otra cosa que mantener que el modelo brugmanniano es el más antiguo y adaptar el hetita a ese modelo. Encaja mal, la verdad. Con lo que se olvidan los paralelos etruscos. Y la idea misma de una evolución dentro del IE.

No aporta, desde este punto de vista, muchas cosas nuevas el Neues Handbuch des Etruskischen de D. H. Steinbauer (St. Katherinen, 1999). Reconoce el parentesco con la estela de Lemnos (p. 363 ss.) y, en alguna medida, con el lidio (p. 366 ss.). Pero estudia sobre todo el vocabulario, apenas la

13 Cf. mi artículo «The new Image of Indoeuropean. The History of a Revolution», IF 97, pp. 1-28, entre otros trabajos.

14 Erich Neu, «Etruskisch - eine indogermanische Sprache Anatoliens?», Historische Sprachwissenschaft 104, 1991, pp. 9-28.

EMERITA. Revista de Lingüística y Filología Clásica (EM) — LXXIII 1, 2005 ISSN 0013-6662 
morfología (cf. p. 387 ss.). No tiene idea sobre la relación del anatolio e IE.

Esta es la situación. Y el resultado de ella es que en los Manuales de Indoeuropeo ${ }^{15}$ y en varias otras obras ${ }^{16}$ para nada se habla del etrusco. Los manuales de etrusco, por su parte, siguen afirmando que se trata de una lengua aislada ${ }^{17}$.

Peor todavía, autores que apuestan decididamente por el origen minorasiático de los etruscos, por ejemplo Beekes y de Palma, callan sobre el detalle de la conexión entre Indoeuropeo y etrusco ${ }^{18}$. $¡ Y$ mientras tanto, aumentan nuestros materiales sobre el etrusco, con la publicación, entre otras cosas, de la tabula Cortonensis y de las laminillas de oro de Pirgi, con traducción púnica, que añaden argumentos a la tesis indoeuopea! ${ }^{19} \mathrm{Y}$ se interpretan como indoeuropeos los numerales etruscos del 1 al 10, que eran el gran argumento de los antiindoeuropeistas ${ }^{20}$.

Este último hecho de que los etruscólogos no lingüistas no se atrevan a enfrentar el problema, mientras que los indoeuropeistas de tradición brugmanniana lo rehuyen, deja al etrusco en el mayor desamparo: como una lengua olvidada, sustraida a la investigación. Es lo que me hace volver sobre el tema. Es un desafío que no debe dejarse incontestado. Por otra parte, conservo algún material bibliográfico, así como cartas de lingüistas referentes a mis artículos. Es esta, me parece, la ocasión de examinar todo esto. Manual.

15 Por ejemplo, los de Szemerényi, Ramat y Villar, bien conocidos. Hay alusiones en mi

16 Por ejemplo, R. Ambrosini, Le lingue indoeuropee, Pisa, ETS Editrice, 1991.

17 Cf. por ejemplo G. y L. Bonfante, La lingua e cultura degli etruschi, Roma, Editori Reuniti, 1985, p. 83. También L. Bonfante en Leyendo el pasado. Antiguas escrituras del cuneiforme al alfabeto, Madrid, Akal, 2003, p. 353 ss. (silencio absoluto sobre los orígenes).

18 Cf. R. S. P. Beekes, The Origin of the Etruscans, Amsterdam, Akademie van Wettenschappen, 2003 (véase mi reseña en Emerita 71, 2003, pp. 374-375); C. de Palma, Le Origini degli Etruschi, Bolonia 2004, p. 132 ss. (laguna en un libro excelente, ni siquiera habla del origen indoeuropeo, solo de coincidencias con lenguas diversas de Asia Menor). Reseño este libro en este mismo número de EMERITA, pp. 161-162.

19 Cf. M. Pittau, Tabula Cortonensis, Lamine di Pirgi e altri testi etruschi, Sassari, Editrice Democratica Sarda, 2000.

20 F. C. Woudhuiuzen, «Etruscan Numerals in Indo-European Perspective», Talanta 2021, 1888-89, pp. 109-127. M. Pittau, «La questione dei numerali etruschi», Atti del Sodalizio Glottologico Milanese, 33, Milán, 1994 (1996).

EMERITA. Revista de Lingüística y Filología Clásica (EM) — LXXIII 1, 2005 ISSN 0013-6662 


\section{Etrusco e Indoeuropeo anatolio.}

Considero la flexion indoeuropea como algo relativamente reciente, algunos arcaismos se han conservado en IE II, especialmente en Anatolio. Véanse bibliografía y opiniones personales, entre otras obras, en Adrados, Nuevos Estudios de Lingüística Indoeuropea, Madrid, 1988, así como en obras anteriores ${ }^{21}$; en libros como Evolución y Estructura del Verbo Indoeuropeo, Madrid, C.S.I.C., 1973; Lingüística Indoeuropea, Madrid, Gredos, 1975; Manual de Lingüística Indoeuropea (en colaboración), Madrid, Ediciones Clásicas, 1995-98; y en algunas publicaciones más ${ }^{22}$.

Es claro que hoy en día tenemos un mejor conocimiento de varias lenguas indoeuropeas: hetita, por supuesto, pero también luvita, licio, lidio, etc. Tenemos, pues, una base mejor para la comparación.

La tesis que hemos venido sosteniendo es que el etrusco no es exactamente ninguna de las lenguas mencionadas, pero sí una lengua anatolia arcaica. Presenta arcaismos que son incluso más antiguos que los paralelos conocidos en estas lenguas. Es, así, una lengua intermedia entre el Indoeuropeo no flexional (IE I) y el flexional de tipo más antiguo, a saber, el tipo monotemático que llamamos IE II. Coincide alternativamente con una u otra de las lenguas anatolias. Presenta también innovaciones, algunas recientes, lo cual no es extraño porque es conocido desde una fecha más tardía que el Anatolio.

He aquí algunos ejemplos de arcaismo, aparte del realmente decisivo: la falta de flexión politemática, ni nominal ni verbal.

1. Frecuentemente el singular tiene en los nombres un valor plural. Una forma especial para plural es generalmente una innovación. Así, por ej., el D. pl. clenarasíi, mientras que el D. sg. clenśi es una forma antigua de sg.-pl. Por otra parte, el etrusco carece de las marcas pluralizantes $-s,-e s,-o s$, pero tiene el IE pl. $-i$ (en el pronombre) y $-a$ (en nombres y adjetivos sustantivados), también - $r$, -er, -ar. Esta última es una innovación etrusca, creada sobre la base de los abstractos y colectivos del IE en $-r$ (cf. gr. ó̉ $\lambda \kappa \alpha \rho$, zĩ $\lambda \alpha \rho$, hitt. keš$\check{s} a r$, mehur, etc.): el sufijo - $r$ - es usado como marca de pl. igual que el n. pl. $-a$, derivado igualmente de temas abstractos y colectivos.

21 Desde «Hethitisch und Indogermanisch», en II. Fachtagung für Idg. und allgemeine Sprachwissenschaft, Innsbruck, 1962, pp. 145-161.

22 Por ejemplo, «The new Image...» ya citada.

EMERITA. Revista de Lingüística y Filología Clásica (EM) — LXXIII 1, 2005 ISSN 0013-6662 
2. El tema puro es usado como $N$. y Ac., a la vieja manera no flexional, pero ocasionalmente el N. tiene ${ }^{*}-s$ (tin o tinś, etc.), el Ac. ${ }^{*} m$ (cf. śpureni de

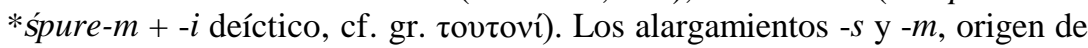
las desinencias, son raramente usados como marcas del sujeto y el complemento. Podemos comparar el Anatolio: el hetita conserva un N.-Ac. kurur al lado de kururaš / kururan; el licio tiene N. $-i,-a$ / Ac. $-i,-a$, pero también un Ac. nasalizado.

3. La declinación heteroclítica del antiguo tipo $-\emptyset /-n$ (- $n$ es G. y D., a veces sin desinencia) se conserva (laut / laut(u)n, puiia / puiian). El hetita conserva el tipo $-r /-n$, otras lenguas anatolias ni el uno ni el otro.

4. El alargamiento $*_{-s}$ no solo da una desinencia de N. sg., sino que a veces se aglutina libremente (G. tinśin, D. tinśi) y es opuesto como desinencia de G. a un N. de tema puro: suthiś, ramthaś. Esto es puro IE. Hay también un G. -śi, -śa que tiene paralelos en luv. cun. -ašši, luv. hier. -aši, luv. hier., het. -ašša (G. y adjetivo). Se trata de diferentes maneras de desambiguar el tipo N.-G. -as.

5. Una desinencia de G. -al, -ale ha sido con acierto comparada a lid. G.-D.-L. sg. $-l$. Es un rasgo anatolio, IE o no. Se combina a veces con -ś, -iś.

6. Las desinencias $-a,-a i,-i$ del hetita y -ahi del licio representan en el origen, según mi propuesta, diferentes grados vocálicos y soluciones fonéticas de temas en $-e H^{I},-H^{3}$, cf. het. N. sg. šuppiš / D.-L. šuppai, šuppa, šuppi. Solo en IE III fueron clasificados entre diferentes temas y se convirtieron en verdaderas desinencias. Por otra parte, el het. y el lic. les añadieron otras desinencias: het. -aya, -iya, -iyaz, lic. -ahedi, -aha, luv. -adi. Cf. etr. G. larthaia, larthia, suthith, suthiti. En etrusco hay también un D. in -e, -e.

7. El etrusco tiene trazas de una oposición entre géneros animado e inanimado. En anatolio es un arcaismo. La rara oposición masc. / fem. ha sido quizá tomada en préstamo del itálico (Aule / Aula), pero los femeninos -i, -ia, -ni parecen innovaciones del IE no compartidas por otras lenguas anatolias.

8. Muchos sufijos adjetivos (-u, -iu, -c, -na, -cva, -ia) así como partículas (-c, sve, ratum, -i deíctico en varios casos y números) son claramente IE, así como varios pronombres ( $\mathrm{mi} / \mathrm{mini}$, ica / eca / ca, ita / eta / ta, etc.) Conservan viejas características indoeuropeas (N. sg. $\sin -s$, N. pl. $-i$, aglutinación, vocal inicial alternando con $\emptyset$, enclisis).

9. El verbo es monotemático, como en anatolio. Esto es muy arcaico, ya que el etrusco parece no haber desarrollado un sistema de desinencias y tener una forma idéntica para singular y plural. Sin embargo, tiene una $3^{\mathrm{a}} \mathrm{sg}$. de la raíz pura o de la raíz + - $a$ y una $2^{\mathrm{a}}$ impv. de la raíz pura o de la raíz + -ti. Esto es claramente indoeuropeo.

10 Hay también arcaismos fonéticos, algunos de ellos presentes también en las lenguas anatolias: $r$ como vocal sonante, tendencia a la desaparición de las

EMERITA. Revista de Lingüística y Filología Clásica (EM) — LXXIII 1, 2005 ISSN 0013-6662 
oclusivas sonoras, oposición vocálica $e(i)$ / $o$. Una innovación compartida con el anatolio tardío es la pérdida de las laringales.

Pero quizá quede todo esto más claro recogiendo el esquema del etrusco y del Indoeuropeo arcaico que he presentado en conferencias y que creo aquí de utilidad.

\section{ETRUSCO ${ }^{23}$}

\section{Indefinición en la flexión nominal.}

Sg. $=\mathrm{Pl}$.

N. clan (tb. pl. clenar), avil, *methlum

G. enaś

$\mathrm{N} .=$ Ac. clan, methlum, Aule, tin, tinś, *śpure

$\mathrm{N} .=\mathrm{G}$. Afunaś, flereś, *tinś

Tema puro G. -aia, -ia (tb. G. -ai-al, D. -i-ale) N. clan, tin, Rumakh, Elina

2. Flexión nominal de tipo IE.

$\mathrm{N}$.

Ac.

G.

D.

L.

N. pl. pron.

Pl. $(*-s):$ tinś

*(-m): śpureni, etan

-(elo)s: suthiś, ramthaś; tinśin, puiian (heterocl.); -śa, -iśa, -aśa, -uśa; -al

$*_{-s i}\left(<*_{-s}+-i\right.$, cf. tinś $\left.-i\right)$

$-t(i)$

$*_{-i}$ : tai, cai, cf. caiti

$-a r$, etc.

3. Temas, adjetivos, pronombres de tipo IE.

Temas

Adjetivos

Pronombres

Adv., conj.

4. Verbo: formas de tipo IE.

Nombre $=$ Verbo

zikh, mulu

23 Véanse más detalles en el Manual citado, II, p. 108 ss. También en «El formante -N y el origen de la flexión heteroclitica del indoeuropeo», Emerita 59, 1991, pp. 5-21 (con alusión al etrusco, p. 14).

EMERITA. Revista de Lingüística y Filología Clásica (EM) — LXXIII 1, 2005 ISSN 0013-6662 


$\begin{array}{ll}\text { Atem./temático } & \text { ar / ara, etc. } \\ \text { Impvo. } & \text {-ti, -thi, -th } \\ \text { Perf. } & \text { teke, } \text { turke } \\ \text { Part. perf. } & -u, \text {-ve }(\text { lupu, tenve) } \\ \text { Otros part. } & \left.\text {-an (mulvan }<*_{\text {-ont }}\right)\end{array}$

\section{INDOEUROPEO ARCAICO}

1. Indefinición en la flexión nominal.
Sg. $=$ pl.
N. het. halkiš, lingaǐ̌, utne, -a (sg. -a / -an), lic. tideimi
G. (Ac. $-i /-\tilde{a})$
$-a s /-a n$
N. = Ac. $\quad$ het. $k u r u r($ pero tb. N. $-a \check{s} /$ Ac. $-a n)$
lic. tideimi
N. = G. het. antuȟ̌a , cf. G. *-osyo ${ }^{*} *_{-o s}+y o$
Tema puro $\quad$ D.-L. šuppa, šuppai, šuppi, lic. -ahi, gr. $\pi$ ó $\lambda \varepsilon 1$

\section{Flexión nominal Indoeuropea.}

N.

Ac.

G.

D., L.:

L.

N. pl. $-\emptyset /-(o) s$

-m (cf. kururaš / -an)

-(e/o)s; heterocl. het. uttar / uddanaš, ai. yus / yusanas; luv. -assa; lid. -al, het. ammel

$-e i,-i$ (de temas puros)

luv. -ati, lic. -adi, lid. -ad


$-i$ (cf. *toi, tb. gr. $\tau$ oĩ $\sigma$, aesl. těxŭ).

3. Temas, adjetivos, pronombres.

Temas $\quad-a,-i,-u$, consonante.

Adjetivos $\quad-i,-u,-n o,-t y o,-t w o$, etc.

Pronombres $\quad(e) k o / e,(e) n o / e,(e) t o / e$, etc.

me, twe

Conj. $\quad k a$

4. Verbo.

Nombre $=$ Verbo $*$ bher,$*$ deik, $* a g$, etc.

EMERITA. Revista de Lingüística y Filología Clásica (EM) — LXXIII 1, 2005 ISSN 0013-6662 
Tem./atemático lat.fero / ferte, sum / es, etc.

Impvo. $\quad$ ai. viddhi, het. arnut, gr. ío $\theta \mathrm{t}$

Perf., aor. $\quad$ ai. dadấśa, gr. $\theta \tilde{\eta} \kappa \varepsilon$

Part. perf. -wot, -wos

Part. pres. $\quad-n t$

\section{Algunos comentarios.}

Era esperable, ya lo adelanté, que mis dos artículos sobre los orígenes del etrusco en el Indoeuropeo II (indoeuropeo arcaico, monotemático, conservado en Asia Menor, pero del que el IE III conserva algunos arcaismos) fueran desatendidos o mejor dicho, ocultados, pese haberse publicado en inglés en dos revistas del máximo prestigio. Hubo, sin embargo, la reacción de Neu, que procedía no del nacionalismo y prejuicio anti-indoeuropeista de los arqueólogos italianos sino del prejuicio de los lingüistas alemanes que se negaban a retirar como más antiguo el modelo IE tradicional (IE III). Ya he recordado mi crítica detallada del artículo de Neu, que hice en mi artículo de la Historische Sprachforschung y que se resume, salvo detalles, en que no comprendió que él estaba hablando de un tipo de IE y yo de otro.

Creo que era necesario exponer todos estos antecedentes para que se comprenda la desgraciada circunstancia en que yo me encontré cuando quise hacer entrar el etrusco en el cuadro del Indoeuropeo II, que era ajeno desde luego a los arqueólogos italianos, pero también a la mayor parte de los indoeuropeistas. Esto explica la reacción de algunos de ellos ante mis trabajos, expuesta en cartas de las que extraido algunos extractos. Creo que con lo dicho está expuesto lo esencial de mi respuesta a sus críticas, así como mi comprensión de las mismas dentro del ambiente general.

Conservo, efectivamente, algunos de estos extractos.

En primer lugar, de una carta de Enrico Campanile. Hace objeciones de detalle sobre algunos morfemas que contienen solo un fonema, lo que puede hacer intervenir el error o que sean préstamos ajenos o constantes tipológicas. No cree que un tema en $-n$ tenga funciones, al tiempo, de G. y D. Pero así es en una fase de creación de la flexión. Y la falta de categorías típicas del IE se explica porque Campanile busca las del IE III, el tradicional, y desatiende las del II, el minorasiático.

R. Ambrosini, que en algunos puntos de la teoría lingüística del Indouropeo ha estado próximo a mí, acepta que el tipo lingüístico del hetita es más

EMERITA. Revista de Lingüística y Filología Clásica (EM) — LXXIII 1, 2005 ISSN 0013-6662 
reciente que el del etrusco, pero propone que la $-s$ del $\mathrm{N}$. viene de la del G.: no ve que son dos morfologizaciones del mismo elemento. Luego, aunque critica la "sombra" de Pallottino (he citado sus palabras), sigue en cierto modo preso en ella: le extraña la falta de datos léxicos indoeuropeos en etrusco (pero cada día hay más), aunque sabe que algunas lenguas, sin renunciar al propio léxico, «sono diventate» indoeuropeas en lo morfológicosintáctico. Pero yo no creo que la morfología indoeuropea del etrusco sea algo secundario, más bien es su esquema básico.

Una carta de J. Faucounau es más positiva: se muestra de acuerdo sobre las desinencias de plural, sobre la identidad N. / Ac., la -s, etc. Pero cree que los femeninos $-i,-i a,-a$ son dativos. $\mathrm{Y}$, sobre todo, se aferra al periindoeuropeo o cuasiindoeuropeo de Kretschmer. No es este el modelo del etrusco, aunque contenga, también, elementos arcaicos.

J. Untermann duda de mi tesis por la escasez en etrusco del léxico indoeuropeo, sobre todo de los numerales. Pero este problema está ya solucionado, véase más arriba. Y duda sobre si la falta de flexión es un rasgo arcaico o reciente: esto se debe a la no aceptación, todavía, de la teoría de los estratos sucesivos del IE, según la he propuesto.

J. Tischler, a su vez, cree que las relaciones entre etrusco y anatolio (que no puede negar) son no genéticas, sino secundarias. Es la vieja teoría italiana, por supuesto que imposible: ¿es que los etruscos fueron de Italia al Egeo y Asía y no al revés?

G. Neumann me remite a Rix y argumenta que el esquema etrusco de la flexión nominal no se compagina con el luvita y licio, este por lo demás es reciente. Hay, pienso, de todos modos, coincidencias suficientes.

Otras cartas (de Shevoroskin, K.-H. Schmidt, Hiersche, de Simone, Oettinger) son más bien de cortesía, no aportan nada. Es afirmativa, en cambio, la de B. Schlerath.

Con esto he intentado trazar un panorama no solo de la teoría del etrusco como IE II, monotemático, de tipo anatolio, sino también del ambiente en que el estudio del etrusco ha estado inmerso, por razones que he explicado. Es una situación que hace difícil el avance en el tema: desde entonces, no conozco progresos. Hay un estancamiento.

Intento romperlo con este artículo, que no hace otra cosa sino criticar viejos prejuicios y mirar directamente a los hechos.

EMERITA. Revista de Lingüística y Filología Clásica (EM) — LXXIII 1, 2005 ISSN 0013-6662 